\title{
Ethylene-Vinyl Acetate Potential Problems for Photovoltaic Packaging
}

Conference Paper NREL/CP-520-39915

May 2006

\section{Preprint}

M.D. Kempe, G.J. Jorgensen, K.M. Terwilliger, T.J. McMahon, and C.E. Kennedy National Renewable Energy Laboratory

T.T. Borek

Sandia National Laboratories

Presented at the 2006 IEEE $4^{\text {th }}$ World Conference on Photovoltaic Energy Conversion (WCPEC-4) Waikoloa, Hawaii May 7-12, 2006 


\section{NOTICE}

The submitted manuscript has been offered by an employee of the Midwest Research Institute (MRI), a contractor of the US Government under Contract No. DE-AC36-99G010337. Accordingly, the US Government and MRI retain a nonexclusive royalty-free license to publish or reproduce the published form of this contribution, or allow others to do so, for US Government purposes.

This report was prepared as an account of work sponsored by an agency of the United States government. Neither the United States government nor any agency thereof, nor any of their employees, makes any warranty, express or implied, or assumes any legal liability or responsibility for the accuracy, completeness, or usefulness of any information, apparatus, product, or process disclosed, or represents that its use would not infringe privately owned rights. Reference herein to any specific commercial product, process, or service by trade name, trademark, manufacturer, or otherwise does not necessarily constitute or imply its endorsement, recommendation, or favoring by the United States government or any agency thereof. The views and opinions of authors expressed herein do not necessarily state or reflect those of the United States government or any agency thereof.

Available electronically at http://www.osti.gov/bridge

Available for a processing fee to U.S. Department of Energy and its contractors, in paper, from:

U.S. Department of Energy

Office of Scientific and Technical Information

P.O. Box 62

Oak Ridge, TN 37831-0062

phone: 865.576 .8401

fax: 865.576 .5728

email: mailto:reports@adonis.osti.gov

Available for sale to the public, in paper, from:

U.S. Department of Commerce

National Technical Information Service

5285 Port Royal Road

Springfield, VA 22161

phone: 800.553 .6847

fax: 703.605.6900

email: orders@ntis.fedworld.gov

online ordering: http://www.ntis.gov/ordering.htm 


\title{
ETHYLENE-VINYL ACETATE POTENTIAL PROBLEMS FOR PHOTOVOLTAIC PACKAGING*
}

\author{
Michael D. Kempe ${ }^{1}$, Gary J. Jorgensen ${ }^{1}$, Kent M. Terwilliger ${ }^{1}$, Tom J. McMahon ${ }^{1}$, Cheryl E. Kennedy ${ }^{1}$, \\ and Theodore T. Borek ${ }^{2}$ \\ ${ }^{1}$ National Renewable Energy Laboratory (NREL), 1617 Cole Boulevard, Golden, CO 80401 \\ 2 Sandia National Laboratories, 1515 Eubank Blvd. SE, Albuquerque, NM 87123
}

\begin{abstract}
Photovoltaic (PV) devices are typically encapsulated using ethylene-vinyl acetate (EVA) to provide mechanical support, optical coupling, electrical isolation, and protection against environmental exposure. Under exposure to atmospheric water and/or ultraviolet radiation, EVA will decompose to produce acetic acid, lowering the $\mathrm{pH}$ and increasing the surface corrosion rates of embedded devices. Even though acetic acid is produced at a very slow rate, it may not take much to catalyze reactions that lead to rapid module deterioration. Another consideration is that the glass transition of EVA, as measured using dynamic mechanical analysis, begins at temperatures of about $-15^{\circ} \mathrm{C}$. Temperatures lower than this can be reached for extended periods of time in some climates. Because of increased moduli below the glass transition temperature, a module may be more vulnerable to damage if a mechanical load is applied by snow or wind at low temperatures. Modules using EVA should not be rated for use at such low temperatures without additional low-temperature mechanical testing beyond the scope of UL 1703.
\end{abstract}

\section{INTRODUCTION}

Polymeric encapsulant materials are used in PV modules to provide electrical insulation and protect them from mechanical damage and environmental corrosion. A well bonded polymer can protect a surface by physically preventing the accumulation of water at its bonding interface. Water can enhance corrosion by providing a means by which by-products can more easily diffuse away from the surface to allow further corrosion. The presence of counter ions (such as $\mathrm{Cl}^{-}, \mathrm{Br}^{-}$, or acetate) similarly enhance corrosion by facilitating the diffusion of metal ions [1]. Furthermore, acidic materials can catalyze the oxidation of metals.

In some of the early work performed at the Jet Propulsion Laboratory in the 1980s [2,3,4] a number of encapsulant materials were investigated, and of those with

\footnotetext{
* This work has been authored by an employee or employees of the Midwest Research Institute under Contract No. DE-AC36-99G010337 with the U.S. Department of Energy. The United States Government retains and the publisher, by accepting the article for publication, acknowledges that the United States Government retains a non-exclusive, paid-up, irrevocable, worldwide license to publish or reproduce the published form of this work, or allow others to do so, for United States Government purposes.
}

adequate mechanical and optical properties, EVA was chosen because it was inexpensive. EVA continues as the dominant encapsulant in the PV industry even though it suffers from non-ideal mechanical and thermal properties, a high diffusivity for water, the need for vacuum lamination in a semi-batch manufacturing process, and the production of acetic acid. As next-generation crystalline silicon wafers are manufactured thinner, the mechanical properties of EVA may not be sufficient, especially at low service temperatures [5].

Because of the success of EVA with silicon-wafer based technologies, it has often been assumed that the generation of acetic acid is not a problem [2]. Typical modules with "breathable" packages should be less affected by acetic acid than those built with impermeable front- and back-sheets (e.g., glass), which trap decomposition products within the package. This type of "non-breathable" package is commonly used in thin-film devices. This problem is exacerbated by the thinness of the device structures, enabling small amounts of surface corrosion to produce significant deleterious effects. Further experimentation is necessary to evaluate the effect of different encapsulants on the stability of thin-film devices to determine if the higher costs of other encapsulants can be justified by an increase in durability.

In this work, we demonstrate that the hydrolysis of vinyl-acetate monomers results in the production of acetic acid, which can accelerate corrosion. We further explain how the mechanical properties of EVA are non-ideal because of the presence of both a melting point and a glass transition temperature $\left(T_{g}\right)$ within the operating limits of a module.

\section{EXPERIMENTAL}

The effused gases from the thermal decomposition of EVA were collected using a heating apparatus and an ion chromatograph (IC) vial that contained a weighed amount of $4.8-\mathrm{mM} \mathrm{KOH}$. This collection solution was tested using IC analysis to determine the acetic acid formation rate. Dynamic mechanical analysis was performed on a TA Instruments Ares Rheometer (equipped with an IGC Polycold Systems Inc. cryogenic refrigeration unit model \#PGC-100 and the Ares forced convection oven) using a rectangular torsional testing fixture. A TA Instruments DSC Q1000 was used for differential scanning calorimetry (DSC). Damp heat $\left(85^{\circ} \mathrm{C}\right.$ and $85 \%$ relative humidity $\left.[\mathrm{RH}]\right)$ exposure was conducted in a Blue $M$ environmental 
chamber. Aluminum mirrors were produced in the sputtering chamber of a Pernicka multichamber vacuum deposition system. The final Al thickness was approximately $800 \pm 25 \AA$.

\section{RESULTS AND DISCUSSION}

\section{Acetic acid formation}

The results for the measurement of acetic acid formation in EVA are summarized in Fig. 1. The slope of the curve indicates an activation energy of $90 \mathrm{~kJ} / \mathrm{mol}$ and extrapolating to the typical average module temperature, $27^{\circ} \mathrm{C}$ [6], predicts $0.00331(\mathrm{ng} / \mathrm{min} / \mathrm{g})$.

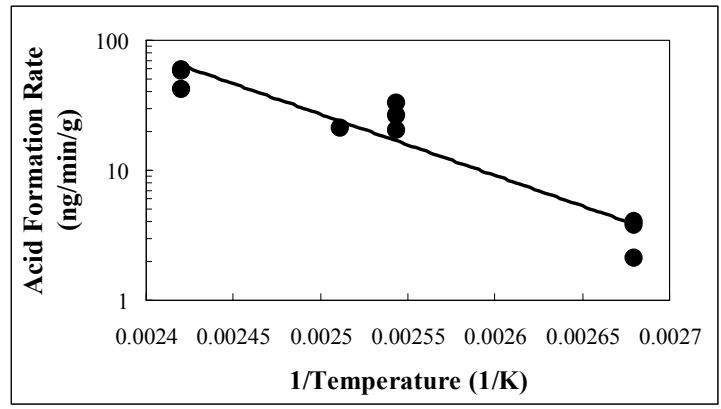

Fig. 1. Nanograms acetate per minute per gram EVA. Acetate was also detected at $80^{\circ} \mathrm{C}(1 / \mathrm{K}=0.00283)$, but was not quantified.

Acetic acid has a pKa of 4.76 , so it will tend to buffer solutions to $\mathrm{pH} 4.76$ corresponding to a hydronium ion concentration of $1.74 \cdot 10^{-5} \mathrm{~mol} / \mathrm{L}$. As an order of magnitude estimate of the time necessary to reach $\mathrm{pH} 4.76$, we assume $3.31 \cdot 10^{-12} \mathrm{~g}_{\mathrm{Acid}} / \mathrm{g}_{\mathrm{EVA}} / \mathrm{min}$ and that the ratio of acetic acid to water in the polymer is the same as would be found for a solution in equilibrium with the polymer. This second assumption provides a relationship between the chemical potential of the acetic acid in the polymer as compared to an aqueous solution. At $27^{\circ} \mathrm{C}$, EVA has at most $0.00223 \mathrm{~g}_{\mathrm{H} 2 \mathrm{O}} / \mathrm{g}_{\mathrm{EVA}}$ [6], and at $\mathrm{pH} 4.76$, there will be equal amounts of acetic acid and acetate ions (or 2.136.10-6 $\mathrm{g}_{\mathrm{Acid}} / \mathrm{g}_{\mathrm{H} 2 \mathrm{O}}$ ). Under these conditions, it will take about 1 day to approach a chemical potential for acetic acid roughly equivalent to $\mathrm{pH}=4.76$. This estimation ignores the large acetic acid production during lamination at $\sim 140^{\circ} \mathrm{C}$ and the affects of UV radiation. A module constructed using EVA will quickly equilibrate to a $\mathrm{pH}$ less than 4.76 if it has an impermeable back-sheet, and to a $\mathrm{pH}$ between 4.76 and 7.0 if it has a breathable back-sheet.

\section{Aluminized glass}

Because $\mathrm{Al}$ is often used for electrical interconnects in PV modules, the ability of EVA to protect it was investigated. In Fig. 2a, aluminized glass substrates were laminated with EVA using a soda-lime glass back-sheet and were exposed to $85^{\circ} \mathrm{C}$ and $85 \% \mathrm{RH}$ for $1003-\mathrm{h}$. In the backlit photograph, some corrosion is visible primarily around the edges where the highest concentration of water was seen. In Fig. $2 \mathrm{~b}$, a similar substrate was exposed to $85^{\circ} \mathrm{C}$ and $100 \% \mathrm{RH}$ for $1003-\mathrm{h}$ and slightly greater corrosion was seen. This demonstrates that corrosion rates with impermeable back-sheets are somewhat limited by moisture ingress rates from the sides.
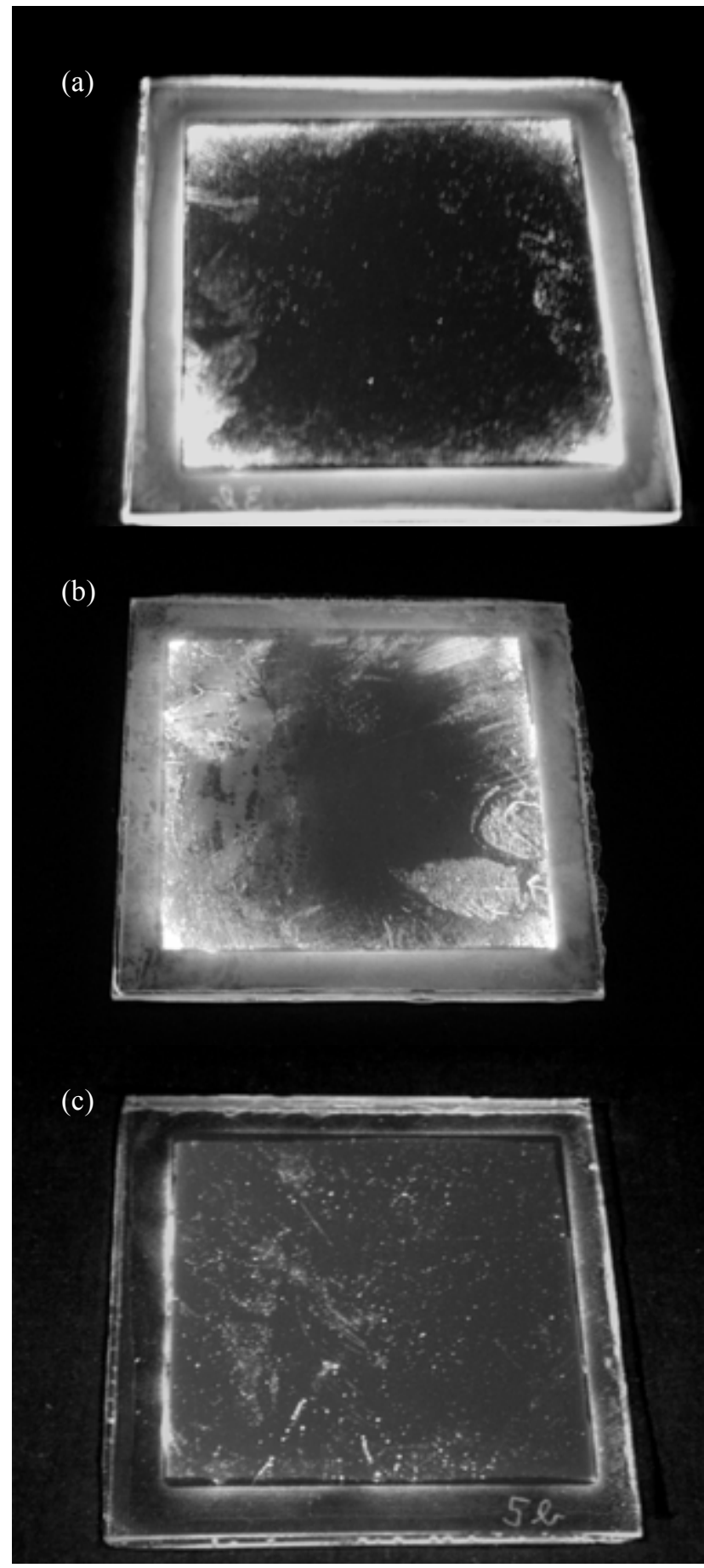

Fig. 2. Aluminum mirror laminated with EVA after $1003-\mathrm{h}$ of $85^{\circ} \mathrm{C}$ (a) with a soda-lime glass back-sheet and $85 \% \mathrm{RH}$ exposure, (b) with a soda-lime glass back-sheet and 100\% RH exposure, and (c) without a back-sheet and $85 \% \mathrm{RH}$ exposure. 
Aluminized glass substrates were also encapsulated without a back-sheet material. When exposed to damp heat $\left(85^{\circ} \mathrm{C}, 85 \% \mathrm{RH}\right)$ for $1003-\mathrm{h}$, these breathable packages do not show significant corrosion of the Al (Fig. 2c). However, when this same breathable construction is exposed to $85^{\circ} \mathrm{C}$ and $100 \%$ humidity (not shown), the $\mathrm{Al}$ is completely oxidized in about $750-\mathrm{h}$. This indicates that saturation is far more corrosive than $85 \% \mathrm{RH}$.

When comparing Fig. 2a (impermeable back-sheet) with Fig. 2c (EVA only), it is apparent that the escape of a volatile component (presumably acetic acid) is enabling the Al coating to withstand damp heat much better. If acetic acid is allowed to escape easily as it is formed, then the $\mathrm{pH}$ of the encapsulant will remain between 4.76 and 7 ; but if it is trapped, the $\mathrm{pH}$ will be a little below 4.76 , leading to faster corrosion rates.

Aluminized glass substrates were also encapsulated with an impermeable glass back-sheet with EVA located only at the center and the edges so that the effects of encapsulation could be directly compared to bare Al (Fig. 3). After 1003-h of exposure, the Al was almost completely removed in areas in contact with the EVA with very little corrosion detectable on the bare Al. In this configuration, the areas covered by EVA have a reduced barrier to corrosion relative to unencapsulated Al. EVA catalyzes corrosion processes presumably because of the presence of acetic acid and a low $\mathrm{pH}$.

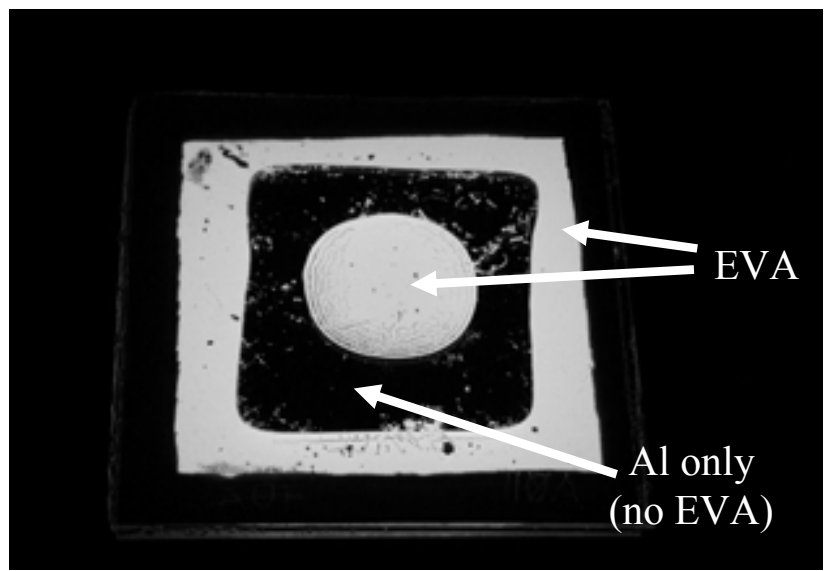

Fig. 3. Aluminum mirror laminated with EVA after $1003-\mathrm{h}$ of $85^{\circ} \mathrm{C}$ and $85 \% \mathrm{RH}$ exposure with a soda-lime glass back-sheet having EVA located only in the center and the outer $\sim 25 \mathrm{~mm}$.

To help quantify the effective chemical potential of the acetic acid produced in EVA, Al mirrors were exposed to the vapors coming off of saturated salt solutions containing varying amounts of acetic acid (Fig. 4a). This was accomplished using an excess of $\mathrm{KCl}$ in an aqueous solution containing up to $20 \%$ (by volume relative to the water content) acetic acid. At $85^{\circ} \mathrm{C}$, this produced a vapor at approximately $79 \% \mathrm{RH}$.

The $\mathrm{pH}$ was estimated using BAKER-pHIX $\mathrm{pH}$ indicator strips. At $1 \%, 4 \%$, and $7 \%$, a pH of approximately $3,2.5$, and 2.5, respectively, was obtained. For higher concentrations, the $\mathrm{pH}$ was at least 2 or lower. The control solutions (no acetic acid) did not oxidize significantly and had an appearance similar to Fig. 2c after 1024-h.
Solutions containing $10 \%, 15 \%$, and $20 \%$ acetic acid experienced severe corrosion after about a 1-day exposure at $85^{\circ} \mathrm{C}$ (Fig. $4 \mathrm{a}$, right side). At $4 \%$ and $7 \%, 200$ to $300 \mathrm{~h}$ were necessary to produce severe corrosion. Finally, the $1 \%$ solution experienced a small but significant amount of oxidation after 1024-h exposure at $85^{\circ} \mathrm{C}$ (Fig. 4b). The amount of corrosion seen at $1 \%$ is similar to that experienced at the perimeter of the samples with impermeable glass back-sheets (e.g., Fig. 2a). Therefore, as a first-order approximation, the 10.2-cm-square samples with glass back-sheets can trap enough acetic acid at $85^{\circ} \mathrm{C}$ to produce an acid environment with a chemical potential approximately equal to a solution at $\mathrm{pH} \sim 3$. However, the $\mathrm{pH}$ was measured at room temperature; the rate of acetic acid loss vs. its production rate changes with temperature, which may affect the final effective $\mathrm{pH}$ attained.

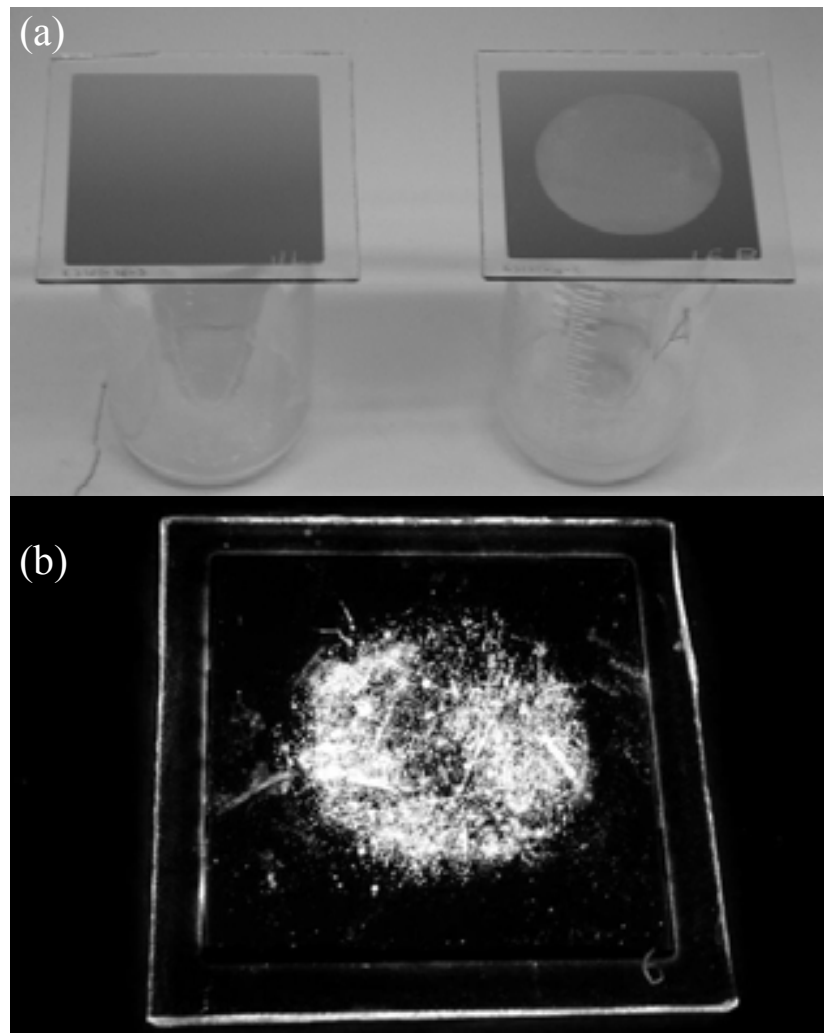

Fig. 4. (a) Aluminum mirror laminated with EVA only. Sample on left placed on top of a jar (mirror/EVA side down) with a saturated salt solution. The sample jar on the right contained $20 \%$ acetic acid. (b) Backlit photo of an aluminum mirror after 1024-h at $85^{\circ} \mathrm{C}$ exposure on top of a jar containing a saturated $\mathrm{KCl}$ with $1 \%$ acetic acid.

These findings are consistent with the fact that $\mathrm{Al}$ oxides become highly soluble in water at $\mathrm{pH} 2.4$ and only slightly soluble at $\mathrm{pH} 4$ [1]. This analysis demonstrates the large potential for EVA to produce a corrosive environment in a sealed package where acetic acid cannot escape.

\section{Rheology}

Because PV encapsulant materials provide mechanical support to the cells [2], rheological 
measurements were made to determine where the phase transitions are and their effect on the dynamic mechanical moduli. In the temperature range of $80^{\circ}$ to $-40^{\circ} \mathrm{C}$, the moduli increased by a factor of about 500 (Fig. 5). This large change in mechanical properties is due to the presence of both a melting point and a glass transition at or near temperatures that are commonly experienced by a module. For frequencies of $100-\mathrm{rad} / \mathrm{s}$, the $T_{g}$ was measured to be $-15^{\circ} \mathrm{C}$, which is much higher than the values of around $-40^{\circ} \mathrm{C}$ frequently reported in the literature [2]. These other sources typically measured the $T_{g}$ using DSC, therefore we performed DSC measurements (at a heating/cooling rate of $10^{\circ} \mathrm{C} / \mathrm{min}$ ) and found the center of the transition at $-33^{\circ} \mathrm{C}$ and $-37^{\circ} \mathrm{C}$ when cooling and heating, respectively (Fig. 6). This kind of a discrepancy is common for polymers, because the two methods are measuring very different phenomena associated with a second-order transition [7]. Because one of the primary purposes of using an encapsulant is to provide mechanical support, the $T_{g}$ measured using dynamic mechanical analysis is more relevant.

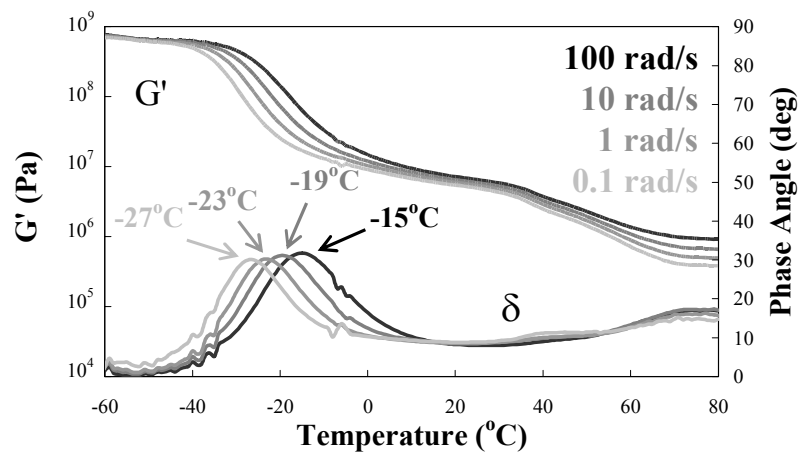

Fig. 5. Dynamic mechanical analysis of cured EVA while heating the sample.

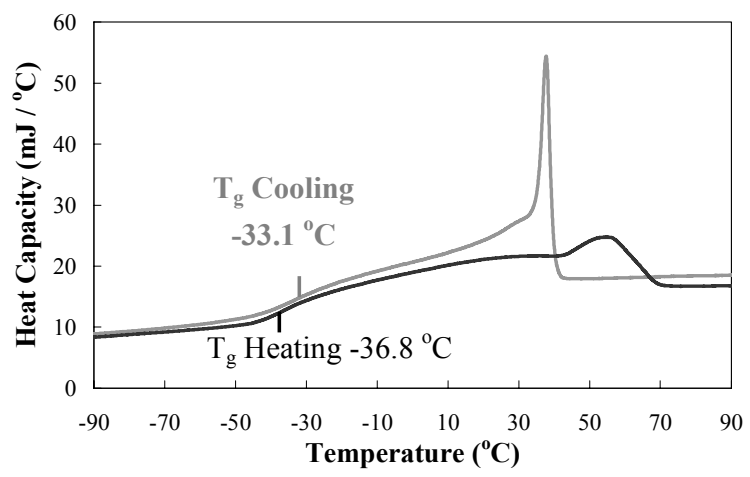

Fig. 6. Heat capacity of cured EVA measured by DSC at a heating $/$ cooling rate of $10^{\circ} \mathrm{C} / \mathrm{min}$.

For many environments, a temperature of $-15^{\circ} \mathrm{C}$ is often reached, making cells in EVA-based modules significantly more susceptible to breakage from sudden impacts and rapid flexing. PV modules are typically rated for use in environments as low as $-40^{\circ} \mathrm{C}$, but this may be too extreme. This low temperature is often based on passing a qualification test (UL 1703 [8]) where the temperature of a module is cycled between $90^{\circ} \mathrm{C}$ and $-40^{\circ} \mathrm{C}$. If high winds were experienced at such low temperatures, the flexing of a module could break the thin cells or debond interconnects. Inclusion of some mechanical bending at low temperatures would be a good addition to UL 1703. Without further testing, a low temperature rating of $-15^{\circ} \mathrm{C}$ may be more appropriate for modules constructed using EVA.

\section{CONCLUSIONS}

Photovoltaic PV devices are typically encapsulated using EVA to provide them with mechanical support, electrical isolation, and protection against environmental exposure. During exposure to water, heat, and/or UV radiation, EVA will decompose to produce acetic acid, thereby lowering the $\mathrm{pH}$ and generally increasing surface corrosion rates. EVA also goes through a $T_{g}$ beginning at about $-15^{\circ} \mathrm{C}$, making its use at low temperatures a significant concern. Despite these shortcomings, EVA has proven to be adequate for most terrestrial environments using silicon-wafer-based devices. Thin-film PV technologies, however, are constructed using layers that are only a few microns thick, making them potentially much more sensitive to surface corrosion than are siliconwafer-based technologies.

\section{ACKNOWLEDGEMENTS}

This work was performed under DOE Contract No. DE-AC36-99G010337.

\section{REFERENCES}

[1] T.E. Graedel, "Corrosion Mechanisms for Aluminum Exposed to the Atmosphere," J. Electrochem. Soc., 136(4) (1989) 204-212.

[2] E.F. Cuddihy, C.D. Coulbert, R.H. Liang, A. Gupta, P. Willis, B. Baum, "Applications of Ethylene Vinyl Acetate as an Encapsulation Material for Terrestrial Photovoltaic Modules," DOE/JPL/1012-87.

[3] E. Cuddihy, C. Coulbert, A. Gupta, R. Liang, "Electricity from Photovoltaic Solar Cells, Flat-Plate Solar Array Project," Final Report, Volume VII: Module Encapsulation, JPL Publication 86-31 Jet Propulsion Laboratory, Pasadena, CA (1986).

[4] J.L. Koenig, F.J. Boerio, E.P. Plueddemann, J. Miller, P.B. Willis, E. F. Cuddiy, "Chemical Bonding Technology: Direct Investigation of Interfacial Bonds," DOE/JPL-1012-120 (1996).

[5] C.P. Chen, "Fracture Strength of Silicon Solar Cells," DOE/JPL Publication 1012-32, Jet Propulsion Laboratory, Pasadena, CA, (1979).

[6] M.D. Kempe, "Modeling of rates of Moisture Ingress Into Photovoltaic Modules," Solar Energy Materials and Solar Cells, Accepted, in press (2006).

[7] K.P. Menard, Dynamic Mechanical Analysis: A Practical Introduction, CRC Press, New York, NY (1999).

[8] UL 1703, Standard for Safety, Flat-Plate Photovoltaic Modules and Panels. 